\title{
Integrating Bicycling and Public Transport in North America
}

\author{
John Pucher, Rutgers University \\ Ralph Buehler, Virginia Tech
}

\begin{abstract}
This paper provides an overview of bike-transit integration in large American and Canadian cities. It begins with an analysis of national trends in bike-and-ride programs such as the provision of bike racks on buses, accommodation of bikes on rail vehicles, and bike parking at rail stations and bus stops. Most of the paper, however, is devoted to case studies of bike-transit integration in six large American cities (San Francisco, Portland, Minneapolis, Chicago, Washington, and New York) and two Canadian cities (Vancouver and Toronto). Much progress has been made over the past decade in coordinating cycling with public transport, but the demand for bikeand-ride far exceeds the supply of facilities in some cities. More funding, in particular, is needed to provide more secure, sheltered bike parking at rail stations and to increase bike-carrying capacity on rail vehicles.
\end{abstract}

\section{Introduction}

Coordinating bicycling with public transport is mutually beneficial, enhancing the benefits of both modes and encouraging more bicycling as well as more public transport use (Brons et al. 2009, Givoni and Rietveld 2007, Hegger 2007, Martens 2004 and 2007, TRB 2005, U.S. DOT, 1998). Bicycling supports public transport by extending the catchment area of transit stops far beyond walking range and at much lower cost than neighborhood feeder buses and park-and-ride facilities for cars. Access to public transport helps cyclists make longer trips than possible 
by bike. Transit services also can provide convenient alternatives when cyclists encounter bad weather, difficult topography, gaps in the bikeway network, and mechanical failures.

In the past, bike-and-ride in North America was limited by low overall levels of cycling and public transport use in most cities, just the reverse of the situation in northern Europe (Bassett et al. 2008, Hegger 2007, Martens 2007, Pucher and Buehler 2008). In recent years, however, both cycling levels and public transport use have risen sharply in the U.S. and Canada, and bike-and-ride trips have been increasing as well. Indeed, in some cities it has been so successful that the demand for bike-and-ride facilities exceeds the available supply (TRB 2005, U.S. DOT 1998).

This paper describes the programs and policies currently being implemented in North America to integrate bicycling with public transport. It starts off with a brief overview of the various kinds of integration and the extent of their implementation. Most of the paper, however, is devoted to case studies of bike-transit integration in two large cities in Canada (Toronto and Vancouver) and six large cities in the U.S. (San Francisco, Portland, Minneapolis, Chicago, Washington, DC, and New York City). The case study analysis compares the type and extent of integration measures undertaken in the various cities, noting the strengths and weaknesses of each city's integration policies. The paper concludes by identifying the most innovative and successful policies in the eight cities and offers policy recommendations for future improvements.

\section{North American Trends in Bike-Transit Integration}

In recent years, levels of cycling and public transport use have reached record highs in both the U.S. and Canada. Between 1995 and 2008, public transport trips rose by 38 percent in the U.S. and by 46 percent in Canada (APTA 2009a and 2009b). Similarly, levels of cycling have increased considerably since 1990. In the U.S., the total number of bike trips to work increased by 32 percent from 1990 to 2005-2007 (averaged) (U.S. Census Bureau 2009a and 2009b). Over the shorter period 1996 to 2006, the number of bike trips to work in Canada rose by an even larger 42 percent (Statistics Canada 2009).

While rising public transport use and increased cycling have provided the rationale for more bike-transit integration, federal funding in the U.S. has provided the necessary financing for a wide range of projects implemented in recent years at the 
state and local government levels (Clarke 2003, Thunderhead Alliance 2007, TRB 2005, U.S. DOT 1998). Indeed, the federal government finances some categories of bike-transit integration projects with an especially high 95 percent federal share. There is no federal funding for urban transport in Canada, but provincial and local governments have provided large increases in funding for public transport and bicycling in recent years, including projects aimed at better integration (CUTA 2008, Pucher and Buehler 2006, Transport Canada 2006).

As documented in this article, virtually every large city in the U.S. and Canada has undertaken a range of measures to promote bike-and-ride. There are five main categories of measures to promote bike-transit integration:

1. provision of bike parking at rail stations and bus stops, with different degrees of shelter and security

2. multi-functional bike stations providing not only parking but also a range of services such as bike rentals, repairs, parts and accessories, bike washing, showers and lockers, and touring advice

3. bike racks on buses, usually exterior, but occasionally interior storage

4. bikes on board vehicles, usually rail vehicles, sometimes with special bike racks, hooks, or even bike cars on trains

5. bike paths, lanes, and on-street routes that lead to public transport stations and stops, thus facilitating the bike's role as feeders and collectors for public transport

\section{Extent of Bike-and-Ride Facilities in North America}

The only available national statistics on bike parking at public transport stops are from recent surveys of 272 American and Canadian transit systems by the American Public Transportation Association (APTA 2006 and 2008a). In the U.S., the supply of bike parking spaces in 2008 was 24,178 at rail stations, 9,005 at bus stops, and 176 at ferry terminals. For the same year, Canadian systems reported 2,892 bike parking spaces at rail stations and 481 at bus stops. Between 2006 and 2008, the supply of bike parking increased by 67 percent in Canada and 26 percent in the U.S. (APTA 2006 and 2008a).

Unattended bike lockers are the main form of secure bike parking at North American public transport stops. Of the 56 large American and Canadian transit systems surveyed by the Transportation Research Board (2005), 14 systems provided bike 
lockers at some of their rail and bus stops, but the actual number of lockers was not reported. The same TRB survey reported eight staffed bike parking stations in 2005, mainly on the West Coast. A few more bike stations have opened since then (Litman 2009).

By far the most important form of bike-transit integration in North America is bike racks on buses. That is not surprising since 60 percent of all public transport trips in the U.S. are by bus (APTA 2009b). Bike racks are inexpensive to install, easy to operate, and do not take up space on the vehicles themselves (TRB 2005). The 2005 TRB survey found that systems throughout the U.S. and Canada provide bike racks on buses and that most systems have eliminated fees they had previously charged for rack use. As shown in Figure 1, the percentage of buses with bike racks almost tripled in the U.S. in only eight years, from 27 percent in 2000 to 71 percent in 2008 (APTA 2008b and 2009a).

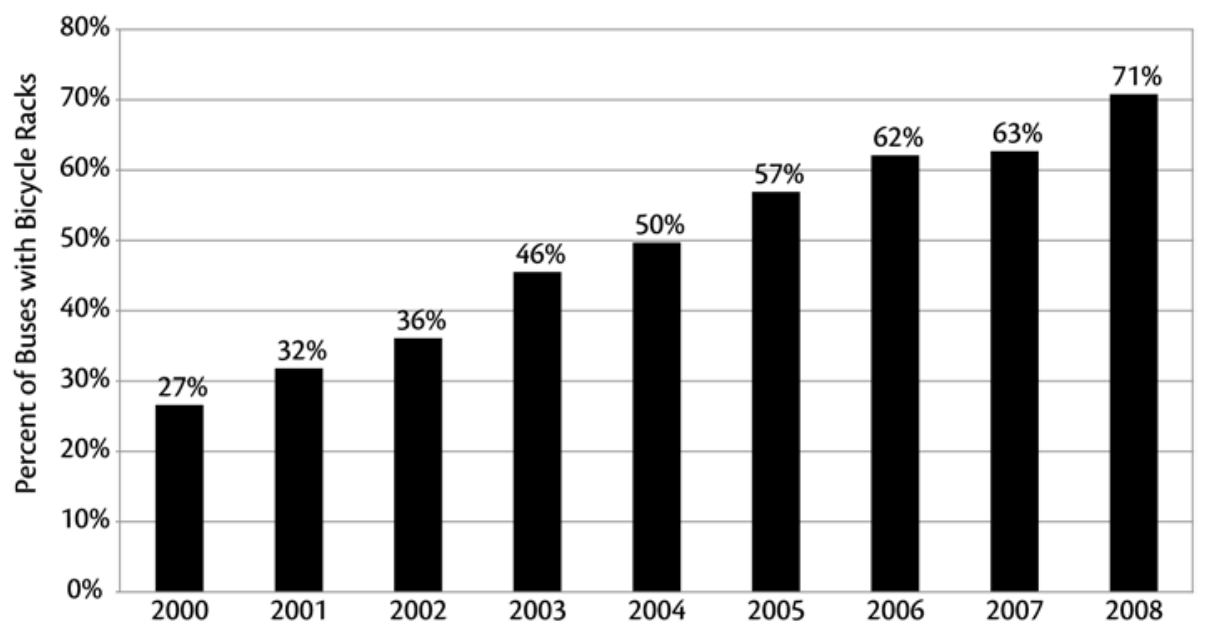

Source: APTA, Public Transportation Factbook 2008, Table 23

Figure 1. Trend in Percentage of Buses with Exterior Bicycle Racks in the U.S., 2000-2008

Another important form of bike-transit integration is the permission to take bikes on board public transport vehicles, since that enables cyclists to ride their bikes to and from public transport stops at both ends of their trips. Few public transport systems permit bikes to be taken on board buses unless they are compact, folding bikes, but most systems permit bikes on light rail, metro, and suburban rail trains, except during 
peak hour periods when crowding makes this infeasible (TRB 2005). Moreover, an increasing number of public transport systems are providing special accommodations for bikes on trains, such as bike racks, bike hooks, special bike holding areas near the doors, and even special bike cars—although rarely (APTA 2008b; TRB 2005).

The last aspect of bike-transit integration is the coordination of bike routes with public transport stops. No national statistics are available on the extent of implementation, and it would be hard to quantify at any rate. Nevertheless, the eight case studies qualitatively assess this aspect of bike-transit integration in each of the cities.

\section{Case Studies of Bike-Transit Integration}

All eight of the case study cities are large, but they vary considerably in metropolitan area population, ranging from 2.2 million in Portland, Oregon to 18.2 million in New York City. The cities also vary widely in their geographic locations, climate, and topography. Most important for this study, they vary greatly in the share of trips covered by bicycling and public transport, as shown in Figures 2 and 3 .

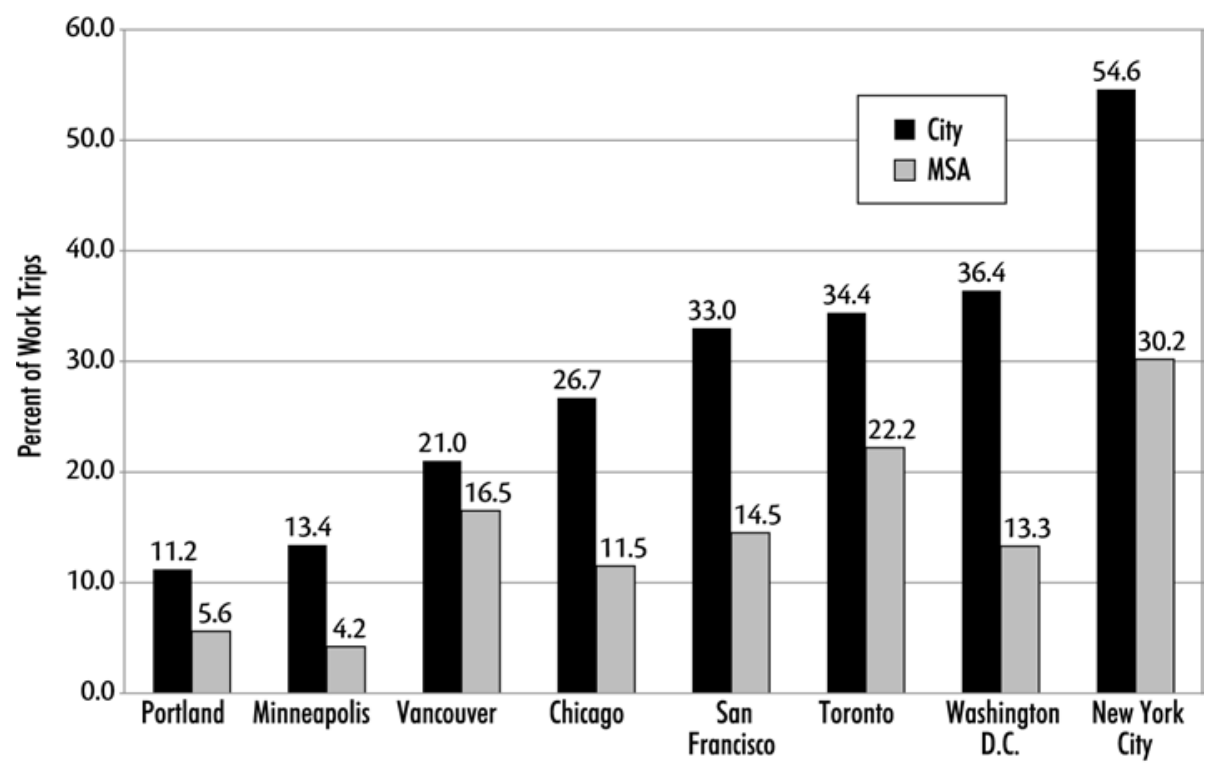

Sources: U.S. Census Bureau (2009b) and Statistics Canada (2009)

Figure 2. Public Transport Share of Work Trips in U.S. and Canadian Cities and Metropolitan Areas, 2006/2007 


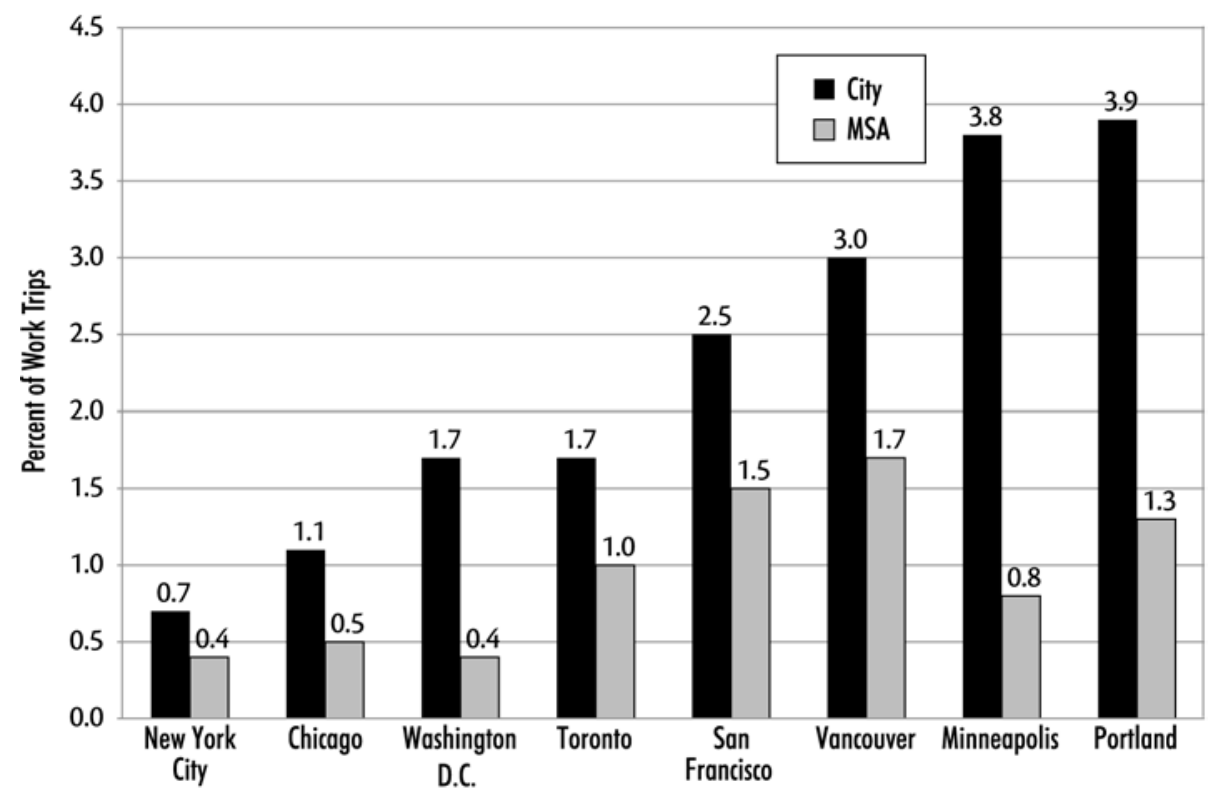

Sources: U.S. Census Bureau (2009b) and Statistics Canada (2009)

\section{Figure 3. Bicycling Share of Work Trips in U.S. and Canadian Cities and Metropolitan Areas, 2006/2007}

In 2006, public transport shares of work trips for central city residents ranged from only 11 percent in Portland to 55 percent in New York (Figure 2). Public transport trip shares for metropolitan areas ranged from 4 percent in Minneapolis to 30 percent in New York. Without exception, public transport use is higher in all eight central cities than in their suburbs.

Levels of cycling also vary greatly among the eight cities (Figure 3). Portland (3.9\%) and Minneapolis (3.8\%) had the highest bike mode shares of work trips in 2006, but Vancouver (3.0\%) and San Francisco (2.8\%) were not far behind. By comparison, cycling to work in New York (0.7\%) and Chicago (1.1\%) is rare. Similar to levels of public transport use, bicycling is much higher in central cities than in the suburbs. 
There are no comparable statistics on levels of bike-and-ride in each of these cities, since the most recent American and Canadian national travel surveys report only the main mode of transport for the work trip. Figures 2 and 3 provide useful background, however, by portraying the overall levels of cycling and public transport in the eight cities and their corresponding metropolitan areas. In general, the higher the levels of both cycling and public transport use, the greater the potential for bike-transit coordination (Hegger 2007, Rietveld 2000, Martens 2004 and 2007).

\section{Variations in Bike-Transit Integration}

Efforts to integrate cycling with public transport vary greatly among the eight case studies. New York City, for example, has done little to promote bike-and-ride, while San Francisco, Vancouver, and Portland have implemented the entire gamut of integration measures. The following section highlights the most important aspects of bike-and-ride policies in each city, noting in particular the strengths and weaknesses of current policies.

Unless otherwise indicated, the information for these case studies was obtained by the authors directly from bicycling planners, public transport systems, metropolitan planning organizations, city transport departments, and non-governmental cycling and sustainable transport organizations in each metropolitan area. The same panel of transit and cycling experts also reviewed the case studies of their cities at several stages to check for accuracy, consistency, and completeness.

\section{San Francisco}

The San Francisco Bay Area has been a leader in bike-transit integration efforts in North America. Bay Area Rapid Transit (BART) provides bike parking at almost all 43 stations, with a total of 4,313 bike parking spaces in 2009, including 1,010 in secure bike lockers. To increase convenience and flexibility, BART has been introducing electronic bike lockers (294 as of 2009), which are available on a first-come, first-served basis and do not require advance subscriptions. Caltrain, the suburban rail line from San Francisco south to Palo Alto and San Jose, provides bike parking at all 32 stations, with a total of 1,100 bike lockers and 400 bike racks.

The San Francisco Bay Area had five of the ten bike stations in the U.S. in 2009: 226 bike parking spaces at two Caltrain stations and 433 spaces at three BART stations. Utilization rates of the bike stations vary widely, from over 100 percent at the Berkeley BART station to only 11 percent at the Palo Alto Caltrain station. BART will soon triple the size of the Berkeley bike station and move it above ground to increase accessibility. 


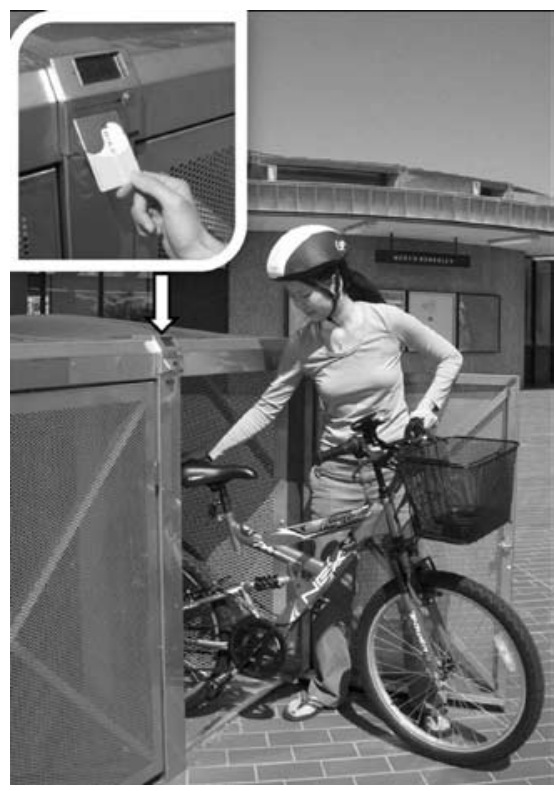

Source: Bay Area Rapid Transit

\section{Figure 4. Electronic Bike Lockers at North Berkeley BART Station}

(Insert shows smart card used to access lockers)

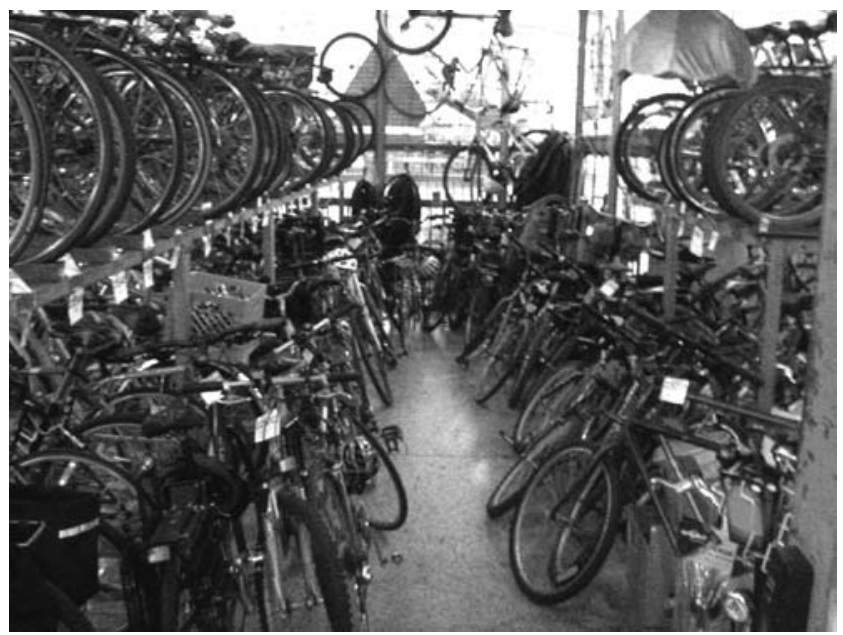

Source: Bay Area Rapid Transit

\section{Figure 5. Bike Station at Berkeley}

BART station is filled to overflowing but will soon be tripled in size to accommodate high demand for bike and ride. 
Cyclists prefer to take bikes on board, however. A 2008 survey found that 72 percent of bike-and-ride passengers carried their bikes with them, compared to only 28 percent who parked them at BART stations. Bikes are allowed on BART trains except during peak hours in the peak direction. Although Caltrain has no time restrictions, cyclists are often denied boarding on rush hour trains because all bike spaces are already occupied. Neither BART nor Caltrain charge a fee for bringing bikes on board. Moreover, Caltrain's lead cars provide special accommodations for 16-32 bikes, depending on time of day and direction of travel. Most of the numerous ferry lines in the Bay Area also permit bikes on board with no extra fee. Folding bikes are allowed on BART and Caltrain at all times, but are not permitted on board San Francisco's MUNI buses, streetcars, cable cars, and light rail vehicles. Complementing bike access to BART and Caltrain services, virtually all buses of all public transport systems in the San Francisco Bay Area are equipped with bike racks, free of charge to cyclists.

Due to the extensive and fine-grained network of bus and rail routes in San Francisco, bike routes often lead to public transport stops, even without any explicit coordination. Outside of San Francisco, where public transport routes and stations are farther apart, many communities make an explicit effort to coordinate bike routes with key stops.

Overall, bike-transit integration efforts in the San Francisco Bay Area have been successful. The percentage of public transport trips combined with cycling has more than tripled since 1990. Nevertheless, several problems remain. For example, it is difficult for cyclists to get across the San Francisco Bay during rush hours, since bikes are prohibited from BART trains in peak directions and not permitted on the Bay Bridge. Similarly, Caltrain has problems accommodating bikes on board in the peak hour and often denies boarding to cyclists.

\section{Portland}

Bike-and-ride in Portland mainly involves bikes on transit vehicles. TriMet, Portland's public transport system, estimates that 10 times more bikes are taken on their LRT vehicles than parked at LRT stations (2,100 vs. 200 per weekday). There are no fees, no permit requirements, and no time of day or directional restrictions for taking bikes on LRT vehicles. Every train has a low-floor car especially designed to facilitate bike access, with waiting areas and four bike hooks located near the doors. But passengers without bikes have priority to board crowded trains. All buses in the Portland area have bike racks, another inducement for cyclists to ride with their bikes instead of parking them. 
By comparison, Portland does not provide much bike parking at train and bus stops. In 2009, there were a total of 670 bike parking spaces at TriMet LRT stops and transit centers (major transfer hubs for several bus or LRT lines). Of those, almost half were bike lockers. In addition, there were city-owned bike lockers at 15 locations in downtown Portland, most of which were near bus or rail services. Portland does not have any bike stations, which is surprising given its high bike mode share and wide range of other pro-bike policies and programs. Bicycling planners and public transport officials plan to improve bike parking at transit stops by installing 196 bike lockers and 168 bike racks at LRT extensions.

Portland cyclists prefer taking their bikes on board transit vehicles. A survey by TriMet indicated that 76 percent of cyclists would not be willing to park their bikes at a transit stop even if there were sheltered and secure bike parking available. The advantage of taking bikes on buses or rail vehicles is that bikes can then be used at both ends of the transit trip. It also reduces the risk of bike theft and vandalism.

Portland carefully and explicitly coordinates its bikeway network with its public transport network. Bike routes are designed to facilitate access to public transport stops. Most transit centers are served by multiple bikeways. Moreover, city planners give special consideration to enhancing bike access to transit stops in outlying areas too far away from the city center for most people to cover by bike alone.

\section{Vancouver}

Metro Vancouver's unique advantage for bike transit integration is TransLink, the fully integrated, multi-modal regional transportation authority. Unlike the other case studies, public transport, major roadways, and bicycling in Vancouver are all handled within the same agency. The coordination of cycling and public transport is obvious and natural in such a multi-modal agency, as reflected in TransLink's plans, funding, construction projects, vehicle procurement, and operating procedures. Over the past 10 years, TransLink has spent more than $\$ 12$ million specifically on bike-transit integration.

As in the San Francisco and Portland areas, all buses in Metro Vancouver are equipped with bike racks. Similar to San Francisco's BART, bikes are allowed on Vancouver's SkyTrain except during peak hours in the peak direction due to problems of overcrowding. Until recently, there were no special accommodations for bikes on SkyTrains, but all future vehicles will provide a special area for bikes in the rear of each car with a leaning rail and fold-up seats. Bikes are allowed at all times on West Coast Express trains for a $\$ 0.50$ charge. SeaBus ferries permit bikes on 
board at all times without charge. Almost all of TransLink's rail and ferry services are fully accessible through elevators, ramps or level boarding, thus facilitating bike-and-ride.

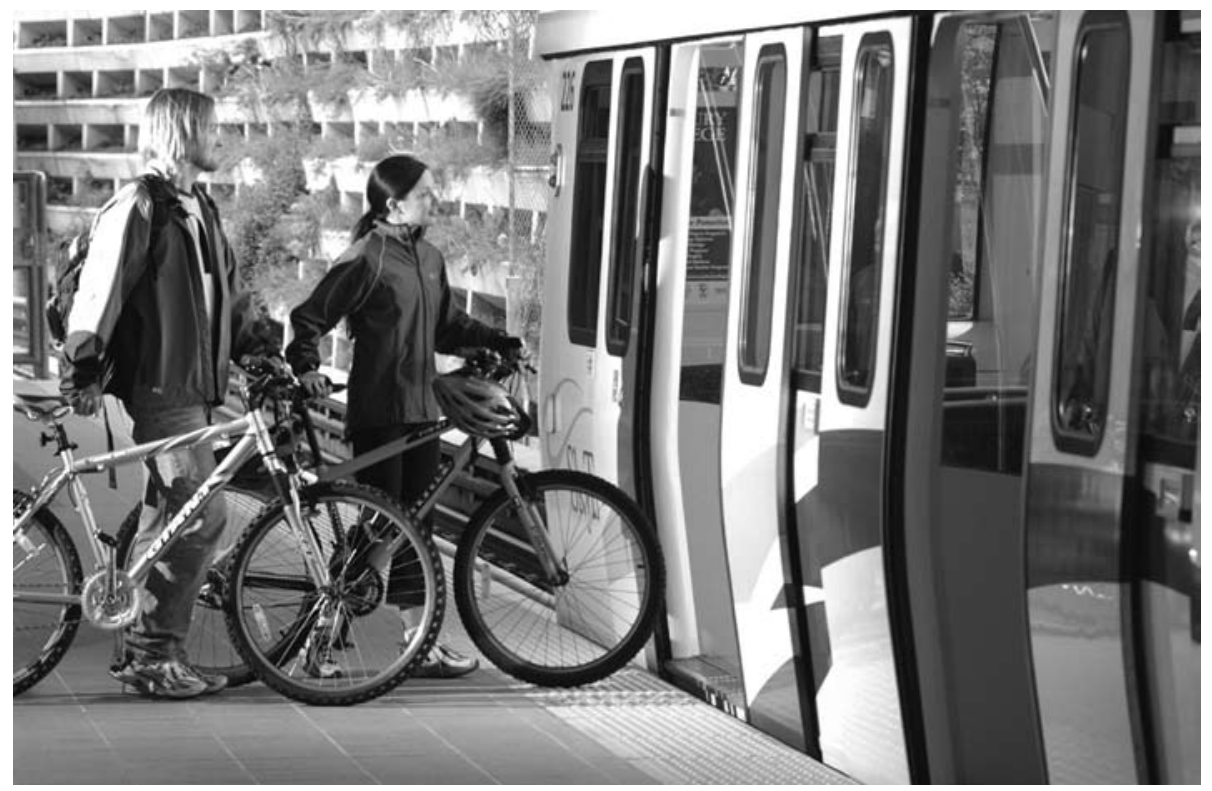

Source: TransLink

Figure 6. Easy Access for Bikes on SkyTrain in Vancouver

There are bike racks at all SkyTrain and West Coast Express rail stations as well as park-and-ride lots and transit nodes with interchanges of several bus or rail lines. In 2008, Vancouver had a total of 1,060 parking spaces at transit stops: 660 spaces in racks and 400 secure bike lockers. TransLink plans to increase the overall supply of bike parking at transit stops in the coming years, with a special focus on improving the quality of bike parking, especially secure short-term bike parking.

TransLink explicitly coordinates bike routes with public transport. For example, the construction of three new SkyTrain lines included traffic-protected, parallel bike routes to foster bicyclist access to public transport. Another aspect of TransLink's multi-modalism is the focused promotion of cycling in central corridors where bus and rail vehicles are the most crowded, and where cycling has the potential to divert some of the overload and reduce crowding. That coordination 
of demand and supply between the two modes is rare and emphasizes the advantages of multi-modal agencies such as TransLink.

\section{Minneapolis}

Although Minneapolis is, by far, the coldest of the eight cities, it has the second highest bike share of work trips, almost as high as Portland's (3.8\% vs. 3.9\%). Public transport's share of work trips is slightly higher in Minneapolis than in Portland (13.4\% vs. $11.2 \%)$, but much lower than in any of the other cities (Figure 2 ).

Metro Transit had 497 bike parking spaces at its light rail and bus stops in 2007: 271 spaces in bike racks and 226 bike lockers. Minneapolis has a staffed bike station, the Midtown Bike Center, with 100 bike parking spaces, repairs, rentals, and a café. It is only a block from the Chicago and Lake Streets transit hub, which serves two of the city's busiest bus lines.

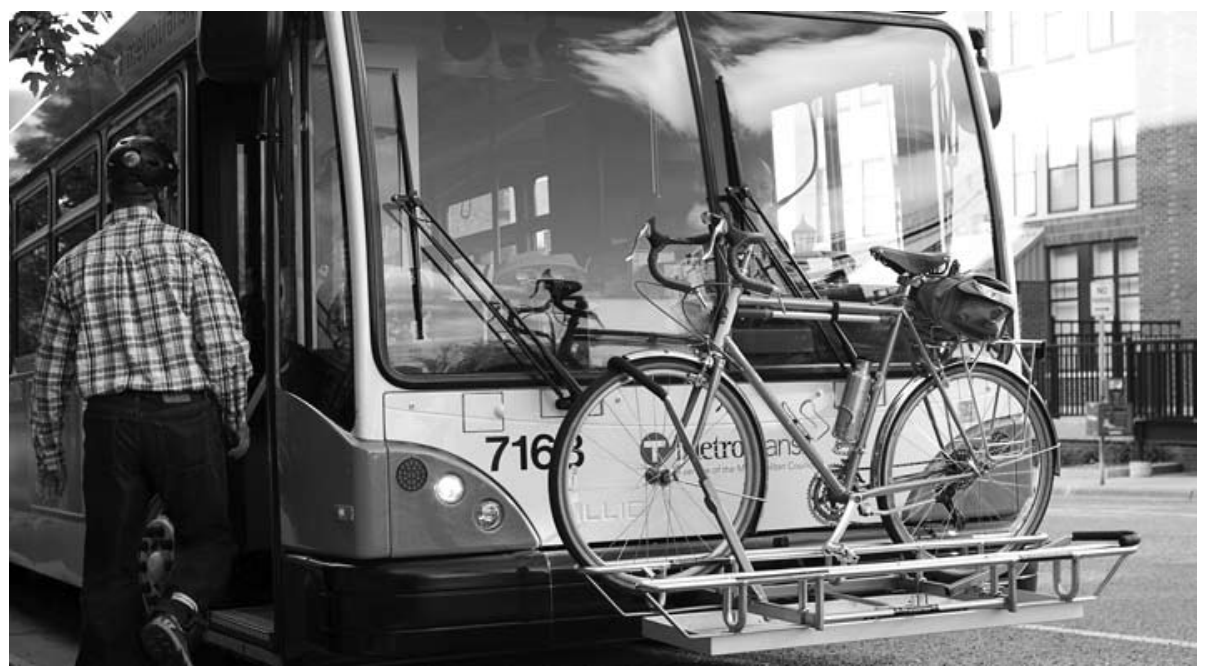

Source: Metro Transit

Figure 7. All Buses in Minneapolis have Bike Racks

All Metro Transit and suburban transit buses are equipped with exterior bike racks, and the city has five stationary bike racks for first-time users to practice loading their bikes. Every light rail vehicle has interior vertical racks that accommodate four bikes. Bike-and-ride has become increasingly popular in Minneapolis. Metro Transit surveys in spring 2007 and fall 2008 found a doubling in the number of bicycles transported on bus racks and a 41 percent increase in bikes on light rail. 
There is no explicit policy of coordinating bike routes and transit stops in Minneapolis, and City officials emphasize the need to improve cycling facilities feeding into public transport stops.

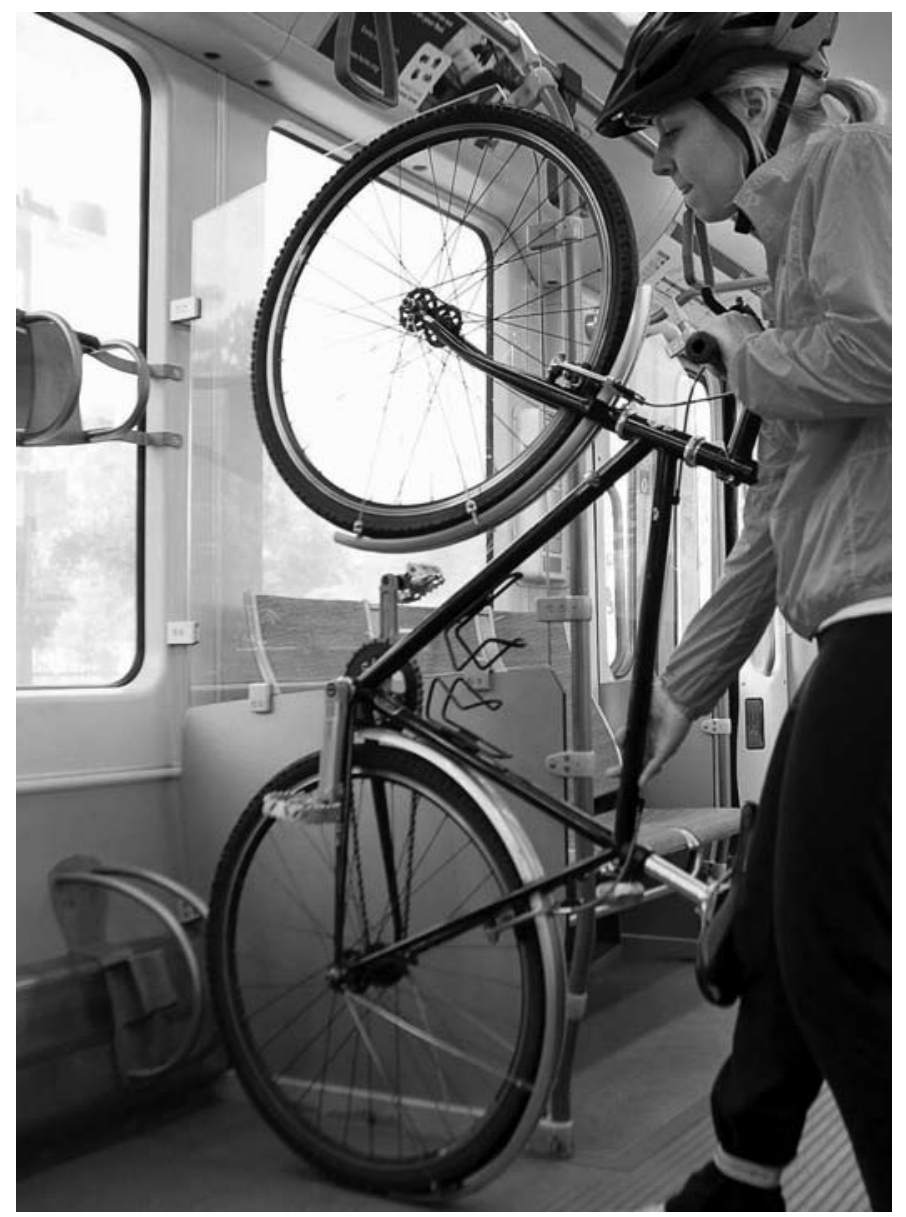

Source: Metro Transit

\section{Figure 8. Vertical Bike Racks on Every Light Rail Vehicle in Minneapolis}

\section{Chicago}

With the second largest transit system in the U.S., Chicago has made impressive efforts to integrate cycling with public transport. Its special distinction lies in the innovative provision of bike parking at rail stations, tailoring the design of parking facilities to each station's particular situation. With 6,420 parking spaces at its rail 
stations, Chicago has about the same amount of bike-and-ride parking as the San Francisco Bay Area and far more than other cities in North America.

There are 2,153 bike parking spaces at 131 of the 143 CTA subway and elevated rail stations and 4,267 spaces at 50 of the 76 Metra suburban rail stations. Moreover, indoor or sheltered parking is available at 83 CTA stations, more than any other transit system in North America. The specific location of bike racks inside the stations provides both weather protection and greater security, since they are usually placed within easy sight of station attendants and other passengers. Chicago is currently installing additional sheltered bike parking for 382 bikes at four CTA stations, and the city has funding to install bike shelters for 250 more bikes in 2010 .

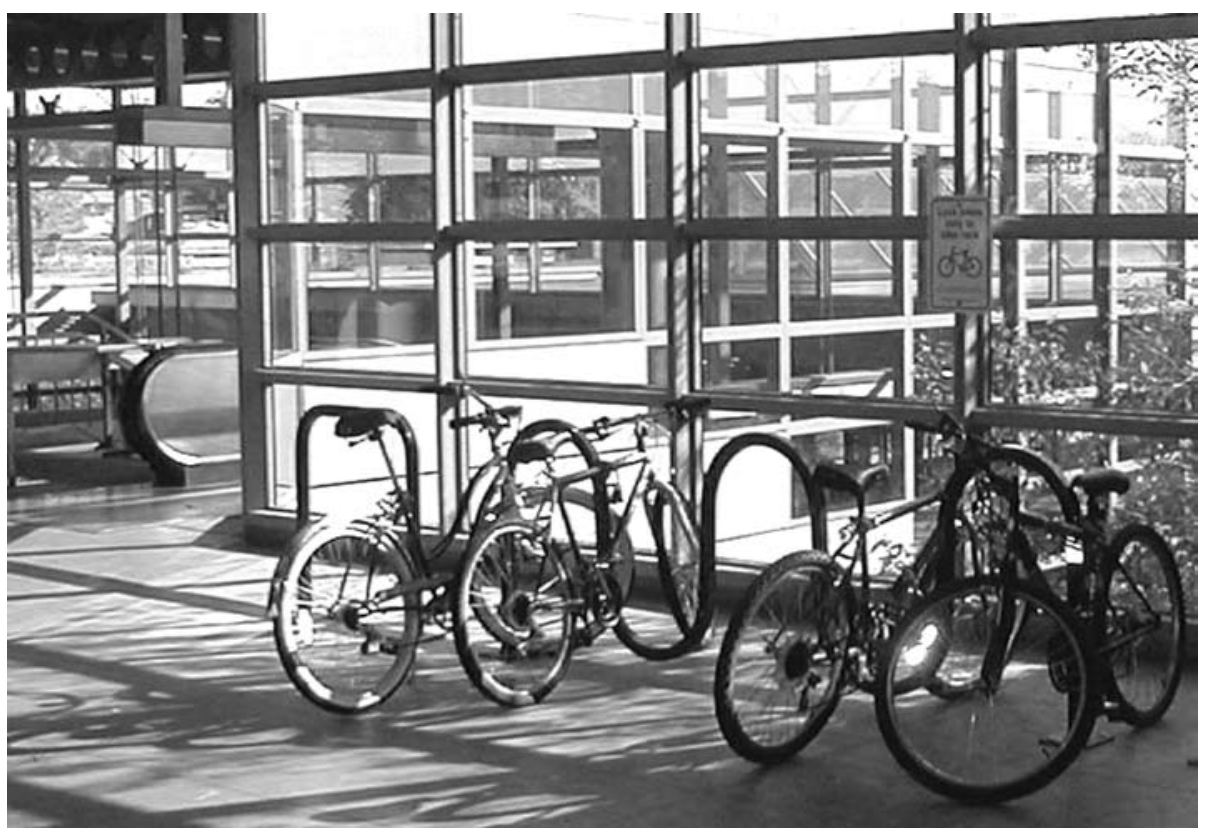

Source: Chicago Transit Authority

\section{Figure 9. Indoor Bike Parking on Concourse of CTA Rail Station in Chicago}

The largest bike station in the U.S. is located in Chicago's Millennium Park, immediately above the terminal station for two of Chicago's suburban rail lines. The bike station is easily accessible from downtown Chicago and the 18-mile Lakefront Trail. It provides secure, indoor parking for 300 bikes as well as convenient lockers, showers and towel service, bike rentals, bike repairs, and guided bicycling tours. 
All of Chicago's buses have bike racks, including CTA buses and PACE suburban buses. Bikes are permitted on CTA and Metra trains except during weekday rush hours. As in most of the other cities, no fees or permits are required for the use of bike racks on buses or for bringing bikes on trains.

The biggest challenge to bike-transit integration in Chicago is the difficult access to train platforms. Because most of the rail lines are so old, only 54 percent of CTA stations and 68 percent of Metra stations are ADA accessible. Thus, cyclists are often forced to carry their bikes up long flights of stairs. Few stations have elevators, and cyclists are not permitted to use escalators.

Chicago DOT, transit agencies, and the cycling community are aware of these problems and have made improvements in bike-transit integration a top priority. Chicago's Bike Plan 2015 sets goals of further expanding and improving bike parking inside and outside of rail stations, remodeling stations to make them more accessible to bikes, providing more park-and-ride facilities, and establishing a second bike station with better transit connections.

\section{Toronto}

With more than 15,000 post-and-ring bike racks throughout the city, Toronto has more bike parking than any other city in North America. That includes bike parking at almost all rail stations. In 2008, there were 1,192 short-term spaces in bike racks at Toronto Transit Commission (TTC) subway stations and 579 short-term spaces in racks at GO Transit suburban rail stations.

Yet there is a severe shortage of secure parking, with only 114 bike lockers in the entire transit network. Consequently, Toronto plans on greatly expanding the supply of secure parking in 2009 and 2010 through installation of more bike lockers and completion of a new bike station at Union Station, the main transit hub in downtown Toronto, providing bus, streetcar, subway, and suburban rail connections. The bike station will provide secure, sheltered parking for 200 bikes. Construction of an even larger bike station at City Hall is planned to begin in 2010. That facility will be close to several bus and streetcar lines. The GO Transit suburban rail system is improving its bike parking by expanding sheltered parking to all stations by the winter of 2009-2010.

As in most cities with high levels of rail transit use, bikes cannot be taken on TTC subways and streetcars during weekday peak hours. Even when permitted, there are no special provisions for bikes on TTC subway cars. Similarly, bikes are not allowed on any GO Transit trains headed toward or leaving Union Station in 
the peak periods. Folding bikes are permitted on all public transport vehicles at all times. Bike access to rail transit is limited by the lack of elevators in most subway stations. Only 41 percent of TTC subway stations are wheelchair accessible, while 75 percent of GO Transit stations are accessible, either through elevators or ramps.

Toronto is making rapid progress equipping its buses with bike racks, which can be used at any time, even during peak periods. In 2008, only 55 percent of TTC buses had bike racks, but all new buses have racks, and every month about 40 older buses are retrofitted with racks. By the end of 2010, all TTC and GO Transit buses will have bike racks, thus facilitating bike-and-ride throughout the region.

There is almost no explicit coordination of bike routes with transit routes and station stops. The many transit stations and fine-grained street network in much of the central city facilitate bike access to TTC stations. In suburban areas, however, many streets are circuitous and do not connect across arterials, making it difficult for cyclists to avoid major arterials while en route to a transit station.

\section{Washington}

Bike parking is available at almost all of Washington's 86 Metrorail subway stations, with a total of 1,800 bike racks and 1,300 bike lockers. The parking facilities are popular, with usage rates at most stations ranging from 50-100 percent. In October 2009, a new bike station with spaces for 150 bikes will open next to Union Station, providing convenient connections to Metrorail as well as suburban trains leaving from Union Station. The bike station will also offer bike rentals, repairs, and accessories as well as storage lockers and changing rooms.

In 2008, a new bike-sharing program began in Washington, similar in technology to the Velib system in Paris, but on a much smaller scale: only 120 bikes compared to over 20,000 bikes in Paris. It facilitates bike-and-ride because 8 of the 10 bikesharing docking stations are at Metrorail stops. The short-term rental bikes can be used to get to and from Metrorail stations, thus serving as feeders and distributors for transit.

Bikes are allowed on Metrorail trains except during morning and afternoon rush hours on weekdays. All 86 Metrorail stations have elevators ( 271 in total) and are ADA accessible, which facilitates access to platforms for cyclists as well, who are, in fact, required to use the elevators and are not permitted on escalators. In contrast to Metrorail, MARC suburban trains never allow full-size bikes on board, and VRE allows bikes only on certain trains. Both rail systems allow folding bikes at any 
time. All 1,450 WMATA buses have bike racks, but some buses run by suburban agencies do not.

In theory, bike plans for the Washington area establish the goal of coordinating bike routes with transit routes, but, in fact, nothing has really been accomplished in this area except by accident.

\section{New York City}

New York's transit systems have done little to promote bike-transit integration, far less than any other city in this study. The Metropolitan Transportation Authority (MTA) does not provide bike parking of any kind at the city's 467 subway stations, so the only option for cyclists is to park on nearby sidewalks. The MTA's suburban railroads, the Long Island Railroad (LIRR) and Metro-North Railroad (MNR), offer bike parking at some of their stations, but MTA has no information on the total number of spaces (MTA 2009).

Compounding the problem of insufficient bike parking along the many subway and suburban rail lines of the MTA, there is no secure bike parking at any public transport terminals in Manhattan. Train, bus, and ferry terminals do not even offer short-term parking in bike racks. Thus, cyclists must seek out the occasional bike rack on sidewalks within a few blocks of the terminals or lock their bikes to traffic signposts, lampposts, or other stationary objects.

NYC subways are unique in permitting bikes on board trains at all times, but it is difficult to get bikes to the platforms. Only 16 percent of New York's subway stations are ADA accessible via elevators or ramps. At the remaining 84 percent of stations, cyclists must carry their bikes up and down long flights of stairs, as they are prohibited from using escalators in stations where they are available. Bikes are allowed on the MTA's two suburban railroads (MNR and LIRR) except during peak hours in the peak direction, but cyclists must register in advance and purchase $\$ 5$ lifetime permits. Folding bikes are allowed at all times.

Bike-bus integration is almost non-existent in New York City. Not a single bus in the MTA's fleet of 5,929 buses has a bike rack. That contrasts sharply with 100 percent of buses equipped with bike racks in most of the other case study cities. Only since spring 2008 have folding bikes been allowed on most MTA buses.

There is no explicit effort to coordinate bike routes with transit routes in New York City. That is not a severe problem in most of the city because the transit network 
is so dense that most neighborhoods are served by a nearby subway or bus line. In the suburbs and the outermost portions of the city, however, the complete lack of bike-transit route integration is a serious shortcoming. Precisely in those lower density areas where cycling would provide an ideal feeder mode to more distant transit stops, bikeways are almost exclusively recreational paths that do not connect to practical destinations such as transit stations.

\section{Summary of Case Studies}

Most of the case study cities have greatly improved the coordination of bicycling and public transport in recent years. They have increased bike parking at transit stops and better accommodated passengers wanting to take their bikes with them on buses and rail vehicles. Only a few transit systems have measured the actual extent of bike-and-ride, but the available evidence is encouraging. In Washington, DC, for example, the number of bicyclists riding on Metrorail increased by 60 percent between 2002 and 2007. At some stations, cyclists accounted for up to four percent of all passenger boardings. In Minneapolis, Metro Transit carries over 250,000 bicycles annually and reports a doubling of bikes on buses between spring 2007 and fall 2008. Roughly four percent of Portland MAX light rail passengers carry their bikes onto the vehicles with them. In the San Francisco Bay Area, the share of passengers accessing BART stations by bike rose from 2.5 percent in 1998 to 3.5 percent in 2008, with an average of 10,920 bike-and-ride trips per day.

As shown in Table 1, there is considerable variation among the eight case studies. The San Francisco Bay Area, for example, provides the full gamut of bikeintegration measures and has been at the vanguard of innovations to promote bike-and-ride. By comparison, New York's transit systems have made few provisions to accommodate cyclists, lagging behind the other case study cities in both the quantity and quality of bike integration measures. All eight of the cities have plans to further improve bike-transit integration. Thus, it seems certain that the promising trends of recent years will continue. 


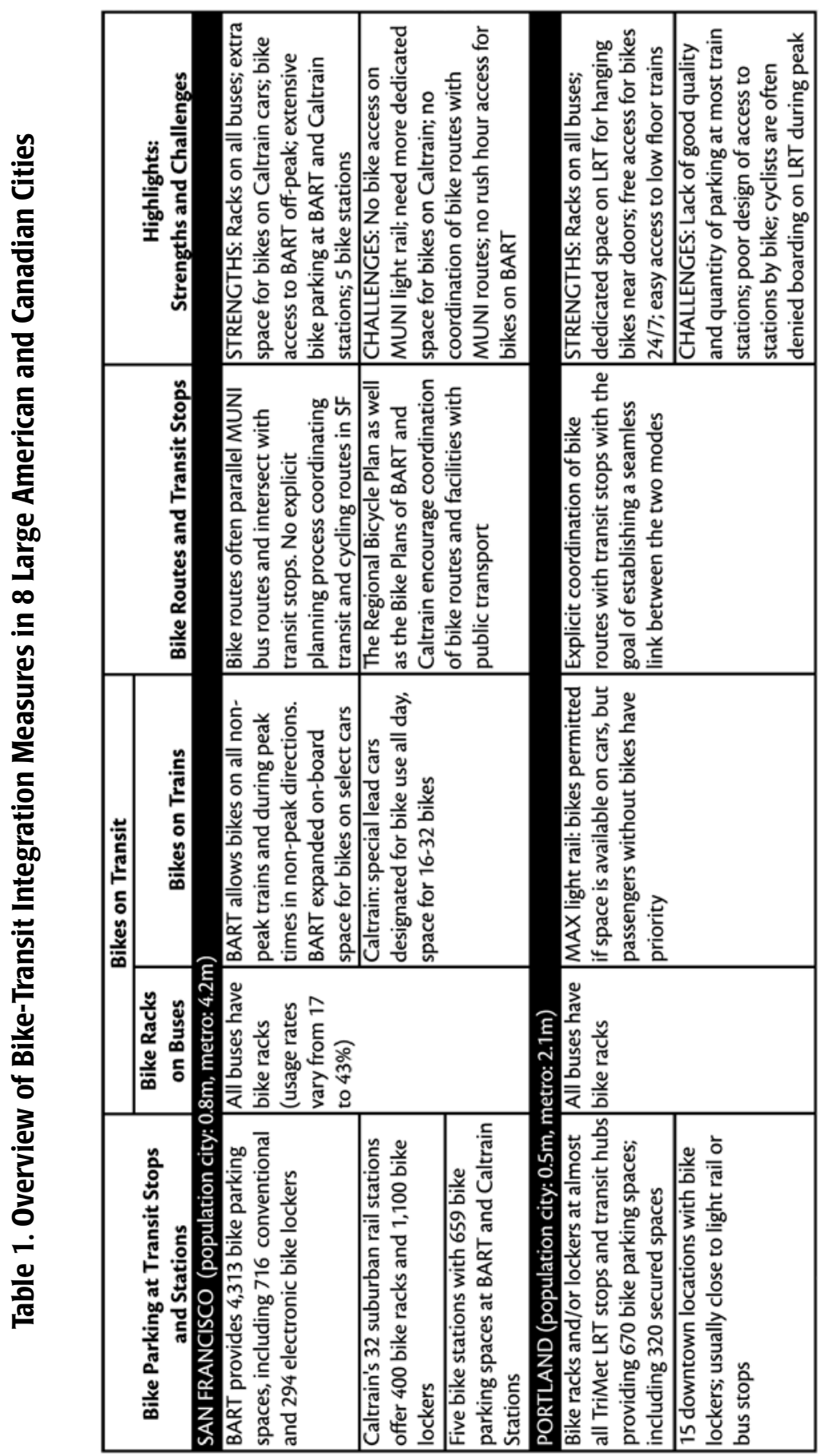




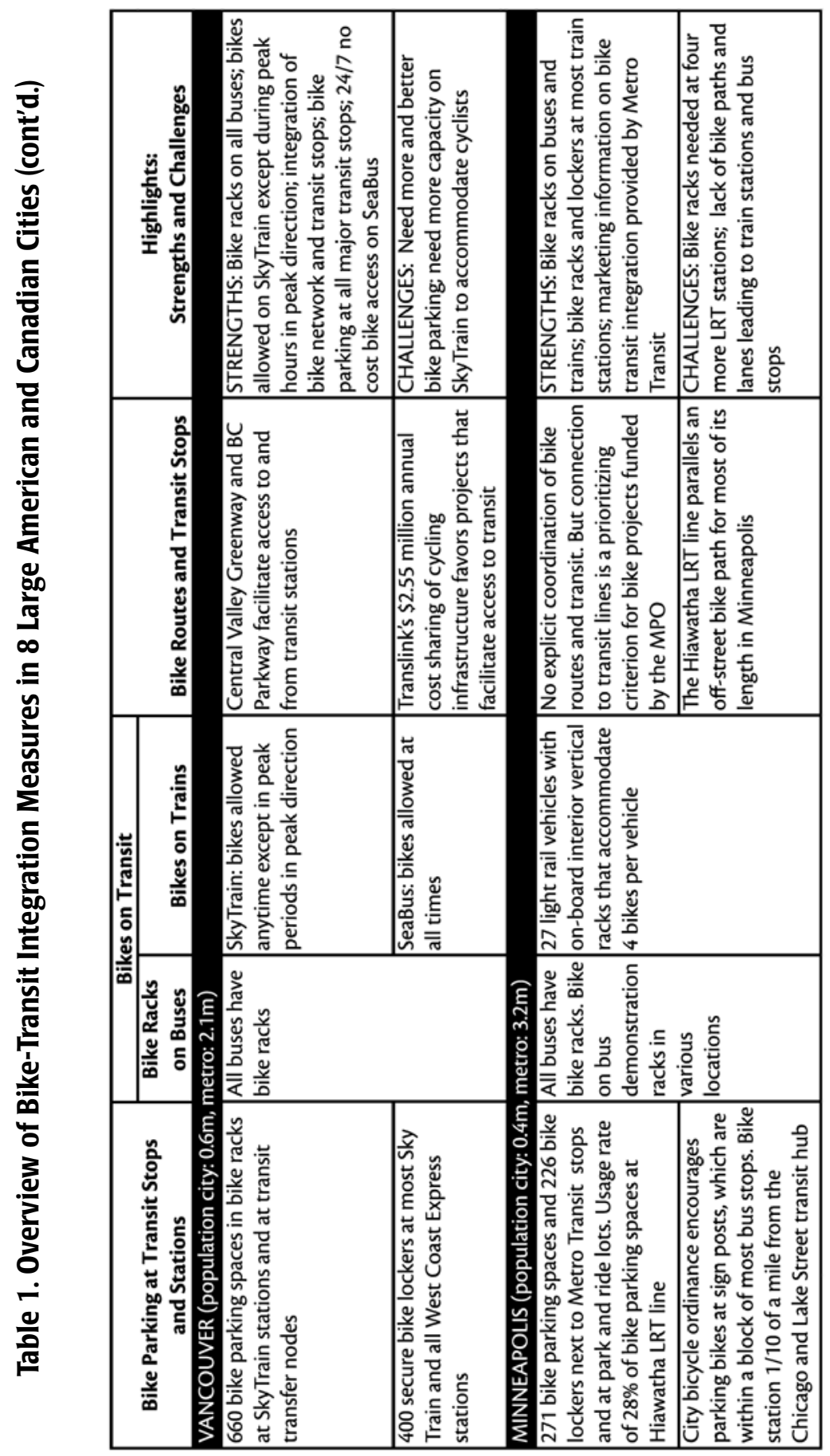




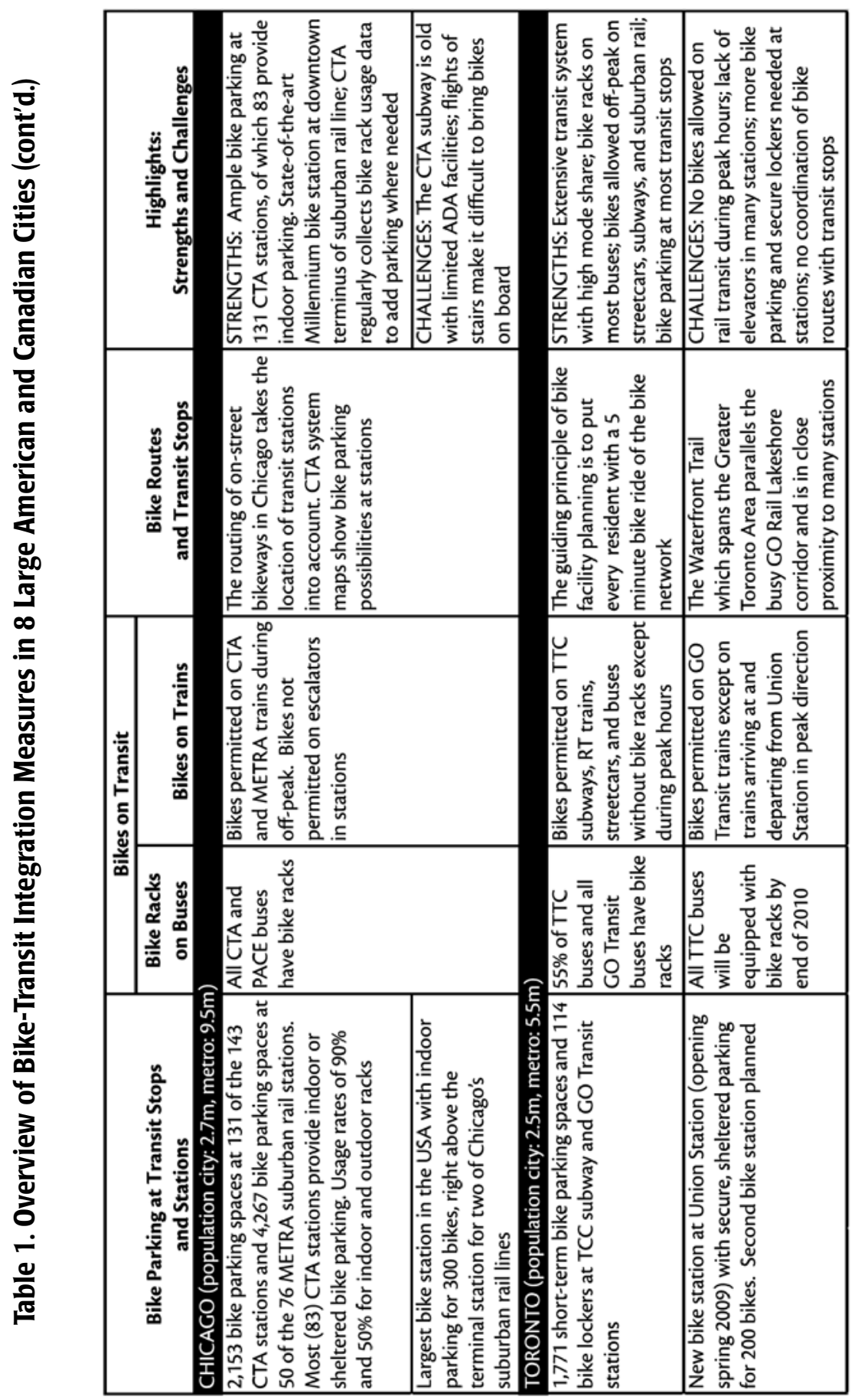




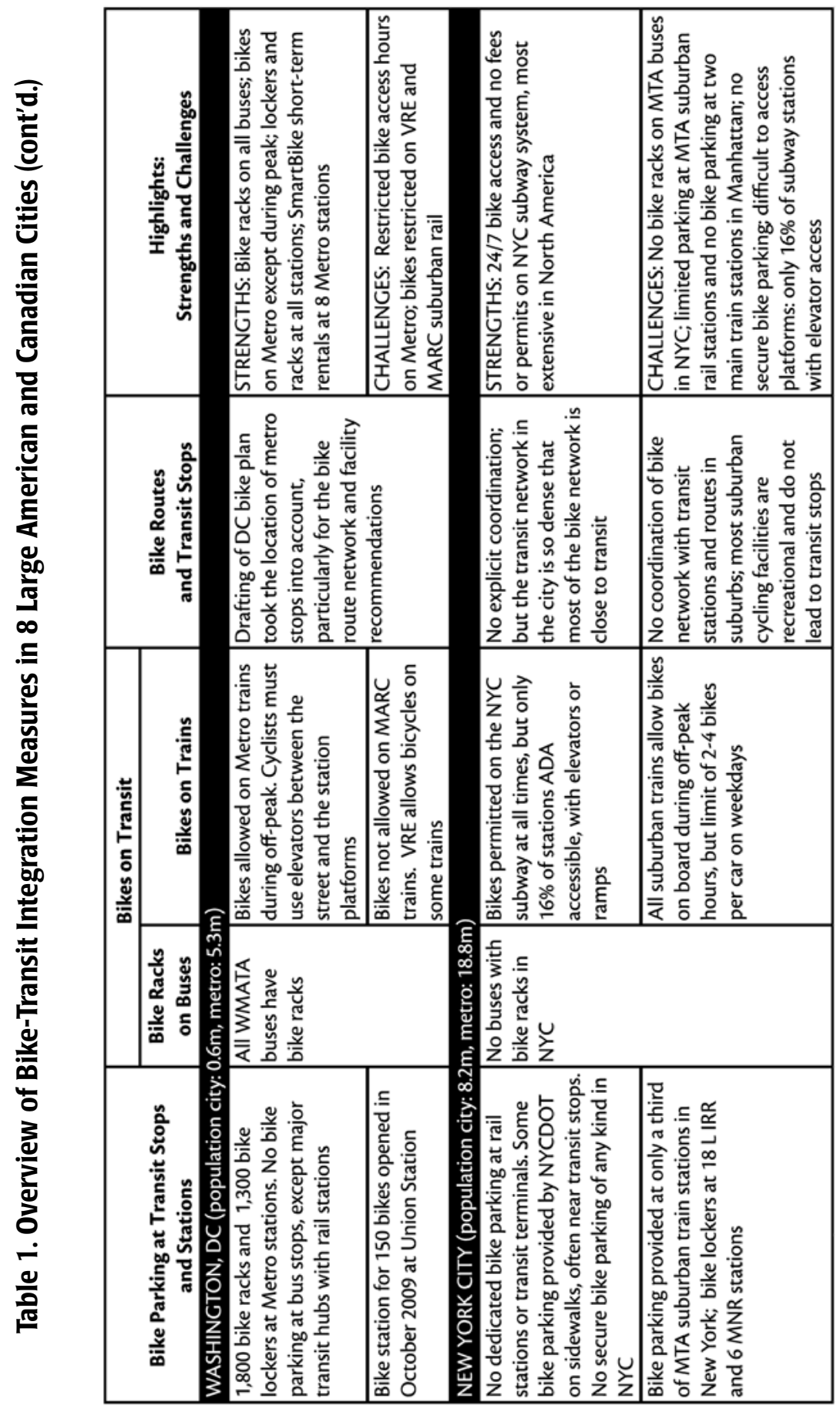




\section{Conclusions and Policy Implications}

North American cities have been making impressive progress integrating cycling with public transport. Since 2000, the percentage of buses with bike racks has almost tripled. Bike-rail integration has also advanced. Most light rail, metro, and suburban rail systems permit bikes on their rail vehicles except during peak hours, and they increasingly provide special accommodations for cyclists such as bike hooks, racks, and rails in special areas of rail cars. Complementing provisions for bikes on transit vehicles, bike parking at transit stops has been vastly expanded over the past 10 years, with large increases in the number of racks as well as improvements in the convenience, security, and shelter of bike parking.

While cycling and public transport have considerable synergies, there are some inevitable conflicts. Surveys in some cities indicate that cyclists prefer to take their bikes with them on rail vehicles so they can use them at both ends of the trip. That can cause problems during peak hours, however, when all available capacity is needed to accommodate passengers and there is no extra room for bikes. Taking bikes on buses is much less of a problem since bike racks are external and do not reduce passenger-carrying capacity. But even bike racks can be filled to capacity during the peak, forcing cyclists to wait for later buses.

Paradoxically, bike-and-ride can become problematic where it is most successful. Capacity problems are most likely to arise in cities with well-used public transport and high levels of cycling. That is why the European approach to bike-and-ride has favored the provision of ample, sheltered, secure bike parking at transit stops instead of accommodating bikes on transit vehicles. Similarly, in North American cities with overcrowding of rail vehicles during rush hours, the focus should probably be on providing improved bike parking at rail stations. Not only is more parking needed, but it should be of higher quality, with more sheltered and secure spaces. Major transit terminals should include multi-service bike stations, such as those in northern Europe. Similar to the concept of "complete streets," an appropriate goal of transit systems in North America should be to provide "complete stations," which fully accommodate the needs of cyclists. That includes making rail platforms more accessible to cyclists, which would also improve accessibility for persons with disabilities.

Such bike-and-ride provisions cost money, but they are much cheaper than parkand-ride facilities for motorists (TRB 2005). Transit systems should shift their focus from park-and-ride to bike-and-ride, which is more cost-effective as well as more environmentally friendly. To encourage that shift, federal, state, and local 
government agencies should vastly expand funding for further improvements in bike-and-ride measures.

\section{Acknowledgments}

The research project on which this paper is based was funded by a grant from the Research and Innovative Technology Administration of the U.S. Department of Transportation. John Neff (American Public Transportation Association), Andy Clarke (League of American Bicyclists) and Gabe Rousseau (U.S. Department of Transportation) provided valuable information and advice on all aspects of the paper. The authors are deeply indebted to the many bicycling experts and transit planners who provided us with detailed information and feedback for the eight case study cities. We list them here grouped by city: San Francisco (Nick Carr, Deirdre Weinberg, Heath Maddox, Laura Timoth, Sarah Syed, Dave Snyder, Leah Shahum, Andy Thornley); Portland (Mia Burke, Roger Geller, Colin Maher); Vancouver (Gavin Davidson); Minneapolis (Shaun Murphy, John Siqveland, James Andrew, Barb Thoman, Tony Hull, Joan Pasiuk); Chicago (Randy Neufeld, Daniel Thomas, Ben Gomberg, Chris Gagnon); Toronto (Dan Egan, Adam Giambrone, Sean Wheldrake, Jennifer Niece, Jana Neumann); Washington (Jim Sebastian, Eric Gilliland, Christine Haldeman, Paul DiMaio); and New York (John Kaehny, Charles Komanoff, Noah Budnick, Caroline Samponaro, Joseph Chan, Ryan Russo, and Joshua Benson).

\section{References}

APTA. 2006. 2006 Transit Infrastructure Database. Washington: American Public Transportation Association.

APTA. 2008a. 2008 Transit Infrastructure Database. Washington: American Public Transportation Association.

APTA. 2008b. 2008 Public Transportation Vehicle Database. Washington: American Public Transportation Association.

APTA. 2009a. 2008 Public Transportation Fact Book. Washington: American Public Transportation Association.

APTA. 2009b. Transit Statistics. Washington, DC: American Public Transportation Association. Accessible at: http://www.apta.com/research/stats/ 
Bassett, D., J. Pucher, R. Buehler, D. Thompson, and S. Crouter. 2008 . Walking, cycling, and obesity rates in Europe, North America, and Australia. Journal of Physical Activity and Health 5: 795-814.

Brons, M., M. Givoni, and P. Rietvield. 2009. Access to railway stations and its potential in increasing rail use. Transportation Research A 43: 136-149.

Clarke, A. 2003. Green modes and U.S. transport policy: TEA-21. In Tolley, R. (ed.), Sustainable Transport (Cambridge, UK: Woodhead Publishing): 433-440.

CUTA. 2008. Canadian Urban Transit Fact Book. Toronto: Canadian Urban Transit Assocation.

Givoni, M., and P. Rietveld. 2007. The access journal to the railway station and its role in passengers' satisfaction with rail travel. Transport Policy 14: 357-365.

Hegger, R. 2007. Public transport and cycling: living apart or together? Public Transport International 2: 38-41.

Litman, T. 2009. Bicycle parking, storage, and changing facilities. Accessible at: http://www.vtpi.org/tdm/tdm85.htm.

Martens, K. 2004. The bicycle as a feedering mode: Experiences from three European countries. Transportation Research Part D 9: 281-294.

Martens, K. 2007. Promoting bike and ride: The Dutch experience. Transportation Research Part A 41: 326-338.

MTA. 2008. MTA and bikes. New York: Metropolitan Transportation Authority. Accessible at: http://www.mta.info/bike/

Pucher, J., and R. Buehler, R. 2006. Why Canadians cycle more than Americans: A comparative analysis of bicycling trends and policies. Transport Policy 13: 265-279.

Pucher, J., and R. Buehler. 2008. Making cycling irresistible: Lessons from the Netherlands, Denmark, and Germany. Transport Reviews 28(4): 495-528.

Statistics Canada. 2009. Employed labour force by means of transportation. Ottawa, Canada: Statistics Canada. Accessible at: http://www12.statcan.ca/ english/census06/data/highlights/POW/Table603.cfm?GH=4\&Lang=E\&O=A $\& S C=1 \& S O=99 \& T=603$.

TRB. 2005. Integration of bicycles and transit. TCRP Synthesis Report 62. Washington, DC: Transportation Research Board, National Research Council. 
Transport Canada. 2003. Sustainable development strategy, 2004-2006. Ottawa, Canada: Transport Canada.

U.S. Census Bureau. 2009a. American fact finder: 1990 Decennial Census, Journey to Work. Washington, DC: U.S. Department of Commerce.Accessible at: http:// factfinder.census.gov.

U.S. Census Bureau. 2009b. American fact finder: 2007 American Community Survey, Journey to Work. Washington, DC: U.S. Department of Commerce. Accessible at: http://factfinder.census.gov.

U.S. DOT. 1998. Bicycles and transit: A partnership that works. Washington, DC: U.S. Department of Transportation, Federal Transit Administration.

U.S. DOT. 2004. National bicycling and walking study: Ten year status report. Washington, DC: U.S. Department of Transportation, Federal Highway Administration.

U.S. DOT. 2007. Bicycle parking and storage. Washington, DC: U.S. Department of Transportation, Federal Highway Administration. Accessible at: http://www. tfhrc.gov/safety/pedbike/pubs/05085/chapt17.htm.

\section{About the Authors}

JOHN Pucher (pucher@rutgers.edu) is a Professor in the Bloustein School of Planning and Public Policy at Rutgers University in New Brunswick, New Jersey. He specializes in comparative research on transport systems, travel behavior, and public policies in the United States, Canada, and Europe. Over the past 12 years, his research has focused on walking and cycling and how public policies could be improved to encourage these most sustainable of all modes of transport. Currently, he is principal investigator of a research project for the U.S. Department of Transportation examining bicycling trends and policies in large American cities.

RALPH BUeHLeR (ralphbu@vt.edu) is an Assistant Professor in the Urban Affairs and Planning Program at Virginia Tech's Alexandria Center. His research seeks to disentangle how international differences in travel behavior are shaped by public policies, spatial development patterns, and demographic and socioeconomic factors. The main goal is to determine what countries can learn from each other to improve the sustainability of their urban transportation systems. Together with Pucher, he is co-principal investigator of a research project for the U.S. Department of Transportation examining bicycling trends and policies in large American cities. 